\title{
PREDICTIVE VALUE OF SERUM TUMOR NECROSIS FACTOR-A LEVEL AND UTERINE ARTERY DOPPLER INDICES AT 11-13 WEEKS' GESTATION IN CASES OF PREECLAMPSIA
}

By

\section{Abdallah Arafa Taemy, Ismael Mohamed Talaat El-Garhy, Osama El- Saeed Ali and Nagah Mohammed Abo-Mohammed*}

Departments of Obstetrics and Gynecology and Clinical Pathology*, Faculty of Medicine, Al-Azhar University

Corresponding author: Abdallah Arafa Taemy, E-mail: abdallah_taemy9090@gmail.com

\begin{abstract}
Background: Cytokines are involved in fetoplacental development, and have been suggested to be the placental factor capable of damaging endothelial cells and contributing to many of the pathophysiological changes associated with preeclampsia. Uterine artery Doppler measurements show that impedance to flow in the uterine arteries decreases with gestational age in normal pregnancies. That impedance to flow is increased in established pre-eclampsia and fetal growth restriction (FGR), and this increased impedance predates the onset of the clinical syndrome of pre-eclampsia or FGR.
\end{abstract}

Objective: To determine the validity of using combined biophysical (uterine artery Doppler) and biochemical (TNf- $\alpha$ ) markers at 11-13 weeks for early screening for pre-eclampsia.

Patients and methods: This study was conducted at the outpatient clinic at Sayed Galal Hospital, Al-Azhar University. This was a prospective cohort study that carried out on three hundred pregnant women who attended to outpatient clinic for antenatal care at 11-13 weeks of pregnancy with 48 missed cases (in the form of 2 IUFDs, 3 preterm labors, 30 miscarriages, and inability to follow 13 cases up).

Results: There were no statistically significant differences between women who developed pre-eclampsia and who did not develop pre-eclampsia as regard maternal age and BMI. The mean concentration of sTNF$\alpha$, was higher in women who developed pre-eclampsia than in women who did not develop pre-eclampsia, and the differences were statistically significant. The best cut off value of the serum TNF- $\alpha$ is $\geq 14 \mathrm{pg} / \mathrm{ml}$ and at this value, we have sensitivity $67.8 \%$; specificity $98 \%$; PPV 79.4\%; NPV 96.4\%. The mean PI of the right and the left uterine arteries was higher in women who developed pre-eclampsia than in women who did not develop pre-eclampsia, and the differences were statistically significant. The best cutoff value of the mean uterine arteries was 1.7 and at this value we have $100 \%$ sensitivity, $84.4 \%$ specificity, $41.7 \%$ PPV, $100 \%$ NPV.

Conclusion: The combination of TNF- $\alpha$ and UA Doppler waveforms almost invariably predicts PET and other adverse pregnancy outcomes; therefore, when used together, biochemistry and ultrasound screening have the ability to improve the sensitivity of screening for PET.

Keywords: Predictive Value of Serum Tumor Necrosis Factor- $\alpha$ Level, Uterine Artery Doppler, Preeclampsia. 


\section{INTRODUCTION}

Preeclampsia is a multisystem disorder of pregnancy defined by the combination of new-onset hypertension and proteinuria that contribute substantially to perinatal morbidity and mortality worldwide. Preeclampsia complicates 2 to $8 \%$ of all pregnancies in the world. The prevalence of hypertensive diseases of pregnancy in Egypt $(4.2 \%)$ had pregnancy induced hypertension, $(3.8 \%)$ had preeclampsia and eclampsia was (0.3\%) (Gabal et al., 2017).

The etiology of preeclampsia remains controversial, but it is now recognized that alterations in the growth and development of placental villi and their underlying vasculature play an important role in the pathogenesis of the disease (Fisher, 2015).

Cytokines are involved in fetoplacental development, and have been suggested to be the placental factor capable of damaging endothelial cells and contributing to many of the pathophysiological changes associated with preeclampsia. TNF- $\alpha$ is an inflammatory cytokine that has been shown to induce structural and functional alterations in endothelial cells (LaMarca, 2012).

In normal pregnancy, at physiologic concentrations, TNF- $\alpha$ acts as a regulatory apoptotic agent that limits the invasive abilities of extravillous trophoblastic cells necessary for appropriate placental anchorage and blood flow toward the intervillous space (Leal et al., 2010 and LaMarca, 2012).

In normal pregnancy the spiral arteries in the placental bed are invaded by trophoblast, which becomes incorporated into the vessel wall and replaces the endothelium, muscular layer and neural tissue. These physiological changes convert the spiral arteries from narrow muscular vessels to wide non-muscular channels independent of maternal vasomotor control. In PE there is impaired trophoblastic invasion of spiral arteries (Fisher, 2015).

Indirect evidence for impaired placental perfusion in pregnancies destined to develop PE has been provided by Doppler studies of the uterine arteries (UtAs) which showed increased pulsatility index (PI) both during the second trimester and also in the first trimester of pregnancy (Akbaş et al., 2014).

One of the most widely studied Doppler indices is the pulsatility index (calculated as the peak systolic flow minus the end diastolic flow divided by the mean flow). An increased pulsatility index has been associated with an increased risk for pre-eclampsia and intrauterine growth restriction (Gujral and Nayar, 2016).

Uterine artery Doppler ultrasonography more accurately predicted pre-eclampsia than intrauterine growth restriction and that the most powerful Doppler index for predicting pre-eclampsia was an increased pulsatility index with notching in the second trimester. For sever pre-eclampsia, they found that an increased pulsatility index or bilateral notching best predicted the condition (Mesinas and Marino, 2012).

The aim of this study was to determine the validity of using combined biophysical (uterine artery Doppler) and biochemical (TNf- $\alpha$ ) markers at 11-13 
weeks for early screening for preeclampsia.

\section{PATIENTS AND METHODS}

This study was conducted in the outpatient clinic at Sayed Galal Hospital Al Azhar University. This was a prospective cohort study that carried on Three hundred pregnant women who attended to outpatient clinic for antenatal care at (11-13) weeks of pregnancy. With 48 missed cases (in the form of 2 IUFDs, 3 preterm labors, 30 miscarriages, and inability to follow 13 cases up).

Inclusion criteria: Gestational age of 1113 weeks of pregnancy (according to a reliable last menstrual period and ultrasound confirmation), singleton pregnancy and age $>20$ and $<35$ years old.

Exclusion Criteria: Maternal systemic disorders or drug use (except usual supplementation, including folic acid), chronic hypertension, diabetes mellitus, collagen vascular diseases, renal disorders, any recent or present fever or infectious disease, malignancies, autoimmune diseases, multiple pregnancies, smoking, any vaginal bleeding, age $>35$ and $<20$ years old, patients refusing participation in the study and patients showing evidence of hyper or hypothyroidism.

\section{All study participants were subjected to the following:}

- History taking in details.

- Physical examination.

- Laboratory Investigations.
- Measuring of Serum tumor necrosis factor alpha (Gomaa et al., 2019).

- Ultrasonography was performed for all women included in the study whether abdominal or transvaginal to confirm viable singleton pregnancy and to confirm gestational age by measuring the fetal crown-rump length making sure that the age of the baby is matching with the age calculated from the last menstrual period.

Agreement for this study was obtained from Department of Obstetrics and Gynecology Ethical Committee Informed consent were obtained from every pregnant women after adequate provision of information regarding the study requirements, purpose and risks.

\section{Statistical analysis:}

Statistical correlation between the introduced database in the first visit (blood pressure values, body weight, body height and body mass index), and the development of pre-eclampsia during the follow-up visits. Analysis of data was done by IBM computer using SPSS (statistical package for social science version 12) as follows: Quantitative variables are presented as mean, SD and the range. Qualitative variables were presented as number. Correlation coefficient test was used to rank different variables against each other positively or inversely. ROC curve was used to find out the best cut off value of certain variable. $P$ value at $\quad \mathrm{P}<0.05$ was considered significant. 


\section{RESULTS}

On follow up of the population of the study, 48 cases missed and 252 cases complete the study, 25 cases developed preeclampsia and were considered cases, while 227 women did not have preeclampsia and were considered controls.
The general data of The patients; age, weight, height and body mass index.

The blood pressure in the total studied groups, systolic blood pressure was $(110.43 \pm 12)$, diastolic blood pressure $(67.91 \pm 8)$ and mean arterial blood pressure (83 \pm 7 ) (Table 1).

Table (1): Demographic data and blood pressure of the studied group $(n=252)$

\begin{tabular}{|c|c|c|c|}
\hline Variables & Minimum & Maximum & Mean+SD \\
\hline Age (years) & 20 & 35 & $21.95 \pm 4.021$ \\
\hline Weight (kg) & 51 & 93 & $68.1 \pm 10.01$ \\
\hline Height (cm) & 152.19 & 182.31 & $163.12 \pm 3.971$ \\
\hline BMI & 16.56 & 38.22 & $25.67 \pm 4.104$ \\
\hline $\begin{array}{c}\text { SBP at 1st visit } \\
\text { (mmHg) }\end{array}$ & 91 & 137 & $110.43 \pm 11.98$ \\
\hline $\begin{array}{c}\text { DBP at 1st visit } \\
\text { (mmHg) }\end{array}$ & 59 & 90 & $67.91 \pm 7.912$ \\
\hline MBP (mmHg) & 67.13 & 102.32 & $83.73 \pm 9.872$ \\
\hline
\end{tabular}

$\mathrm{BMI}=\mathrm{WT}(\mathrm{kg}) / \mathrm{Ht}^{2}(\mathrm{~cm})$

Mean B. $\mathrm{P}=$ DiastolicB.P+1/3 pulse pressurepulse pressure $=($ systolic B.p- Diastolic B.P $)$

The range of TNF - $\alpha$. in normal patients was (3-17) and the mean was (7.14 \pm 3.05$)$. The range of TNF $-\alpha$. in PET patients is (6-28) and the mean is (14.6 \pm 5.8$)$ (Table 2).

Table (2): Serum level of TNF - $\alpha$. in Group 1 (normal patient) and Group2 (PET patient)

\begin{tabular}{|c|c|c|c|c|c|}
\hline Parameters & & & ge & & $95 \%$ \\
\hline $\begin{array}{l}\text { Serum TNF- } \\
(\mathrm{pg} / \mathrm{ml})\end{array}$ & & Minimum & Maximum & & Mean \\
\hline Group 1 & 227 & 3 & 17 & $7.14 \pm 3.05$ & $3.91-7.25$ \\
\hline Group 2 & 25 & 7 & 28 & $14.6 \pm 5.8$ & 13.73-17.25 \\
\hline
\end{tabular}

There was a negative correlation between TNF $-\alpha$ and (Weight, BMI). but it was not significant. This table shows there is highly significant negative correlation between TNF $-\alpha$ and (Apgar score, GA at time of delivery).
There was a positive correlation between TNF $-\alpha$ and age, and significant positive correlation between TNF $-\alpha$ and (uterine artery Doppler PI, blood pressure at first visit) (Table 3). 
Table (3): Correlation of $\mathrm{TNF}-\alpha$ with personal and clinical parameters

\begin{tabular}{|c|c|c|}
\hline TNF- $\alpha$ & Correlation Coefficient & P-Value \\
\hline Age & 0.077 & 0.131 \\
\hline Weight & -0.004 & 0.817 \\
\hline BMI & -0.03 & 0.523 \\
\hline RT. Uterine P.I & 0.317 & $<0.001$ \\
\hline LT. Uterine PI & 0.441 & $<0.001$ \\
\hline Apgar score & -0.331 & $<0.001$ \\
\hline GA at time of delivery & -0.401 & $<0.001$ \\
\hline SBPat1st visit & 0.413 & $<0.001$ \\
\hline DBPat1st visit & 0.221 & $<0.001$ \\
\hline MBP & 0.372 & $<0.001$ \\
\hline
\end{tabular}

ROC Curve

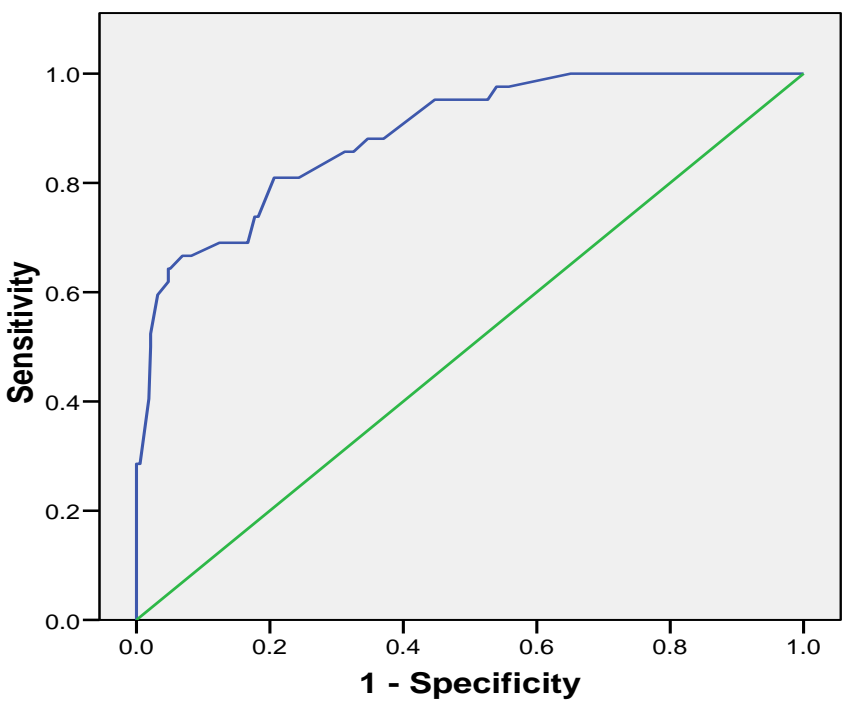

Diagonal segments are produced by ties.

Figure (1): Receiver operator characteristics (ROC) curve was constructed for serum level of TNF- $\alpha$ as predictor of development pre-eclampsia

Area under the curve was 0.887 [95\% CI (0.836 to 0.951), $\mathrm{p}<0.0001]$ (Table 4).

Table (4): Area under the ROC Curve for Serum TNF- $\alpha$ as Predictor of Preeclampsia

\begin{tabular}{|c|c|c|c|}
\hline & AUC & P (Area=0.5) & $95 \%$ CI \\
\hline $\begin{array}{c}\text { TNF- } \alpha \text { as Predictor of } \\
\text { Developing Pre-eclampsia }\end{array}$ & $\mathbf{0 . 8 8 7}$ & $\begin{array}{c}<0.0001 \\
\text { HS }\end{array}$ & 0.836 to 0.951 \\
\hline
\end{tabular}

$\mathrm{AUC}=$ area under the curveHS $=$ highly significant $95 \% \mathrm{CI}=95 \%$ Confidence Interval

The best cutoff point of serum TNF- $\alpha$ as predictor of developing pre-eclampsia was $\geq 14 \mathrm{pg} / \mathrm{ml} \quad[$ Sensitivity $67.8 \%$; specificity 98\%; PPV 79.4\%; NPV 96.4\%, overall accuracy $90 \%, \mathrm{LR}+71.5$, LR32.4] (Table 5). 
ABDALLAH ARAFA TAEMY et al.,

Table (5): Diagnostic Accuracy of Serum TNF-- $\alpha$ as Predictor of Pre-eclampsia

\begin{tabular}{|c|c|c|c|c|c|c|c|}
\hline & Sensitivity & Specificity & PPV & NPV & $\begin{array}{c}\text { Overall } \\
\text { Accuracy }\end{array}$ & LR+ & LR- \\
\hline $\begin{array}{c}\text { TNF- } \alpha \text { as } \\
\text { predictor of } \\
\text { developing } \\
\begin{array}{c}\text { Preeclampsia } \geq 14 \\
\text { pg/ml }\end{array}\end{array}$ & $\mathbf{6 7 . 8 \%}$ & $98 \%$ & $79.4 \%$ & $\mathbf{9 6 . 4 \%}$ & $90 \%$ & 71.5 & 32.4 \\
\hline
\end{tabular}

PPV positive predictive value NPV negative predictive value

LR+ positive likelihood ratio LR- negative likelihood ratio

This table shows the range of PI. in normal patients is $(0.7-2.5)$ the mean is $(1.13 \pm 0.399)$. The range of PI. in PET

patients is (1.7-2.9) the mean is $(2.51 \pm$ 0.26) (Table 6).

Table (6): Level PI in Group 1 (normal patient) and Group2 (PET patient)

\begin{tabular}{|c|c|c|c|c|c|}
\hline Parameters & $\mathrm{N}$ & \multicolumn{2}{|c|}{ Range } & \multirow{2}{*}{ Mean \pm SD } & 95\% CI \\
\cline { 3 - 4 } & Minimum & Maximum & \\
\hline $\begin{array}{c}\text { Group 1: } \\
\text { PI mean }\end{array}$ & 227 & 0.7 & 2.5 & $1.13 \pm 0.399$ & $14.01-1.68$ \\
\hline $\begin{array}{c}\text { Group 2: } \\
\text { PI mean }\end{array}$ & 25 & 1.7 & 2.9 & $2.51 \pm 0.26$ & $\mathbf{2 . 3 3 - 2 . 5 3}$ \\
\hline
\end{tabular}

This table shows there is negative correlation between PI and (Weight, BMI). This table shows there is highly significant negative correlation between PI and (Apgar score, GA at time of delivery). This table shows there is positive correlation between PI and age. This table shows there is highly significant positive correlation between PI and (TNF-Alpha and blood pressure at first visit) (Table 7).

Table (7): Correlation of PI with personal and clinical parameters

\begin{tabular}{|c|c|c|}
\hline Variables & Mean PI & P Value \\
\hline Age & .052 & .286 \\
\hline Weight & -.023 & .637 \\
\hline BMI & -.051 & .296 \\
\hline RT. Uterine P.I & $.839(* *)$ & $<0.001$ \\
\hline LT. Uterine PI & $.926\left(^{* *}\right)$ & $<0.001$ \\
\hline TNF-Alpha & $.534(* *)$ & $<0.001$ \\
\hline Apgar score & $-.353(* *)$ & $<0.001$ \\
\hline GA at time of delivery & $-.399(* *)$ & $<0.001$ \\
\hline SBP at 1st visit & $.333(* *)$ & $<0.001$ \\
\hline DBP at 1st visit & $.312(* *)$ & $<0.001$ \\
\hline MBP & $.342(* *)$ & $<0.001$ \\
\hline
\end{tabular}




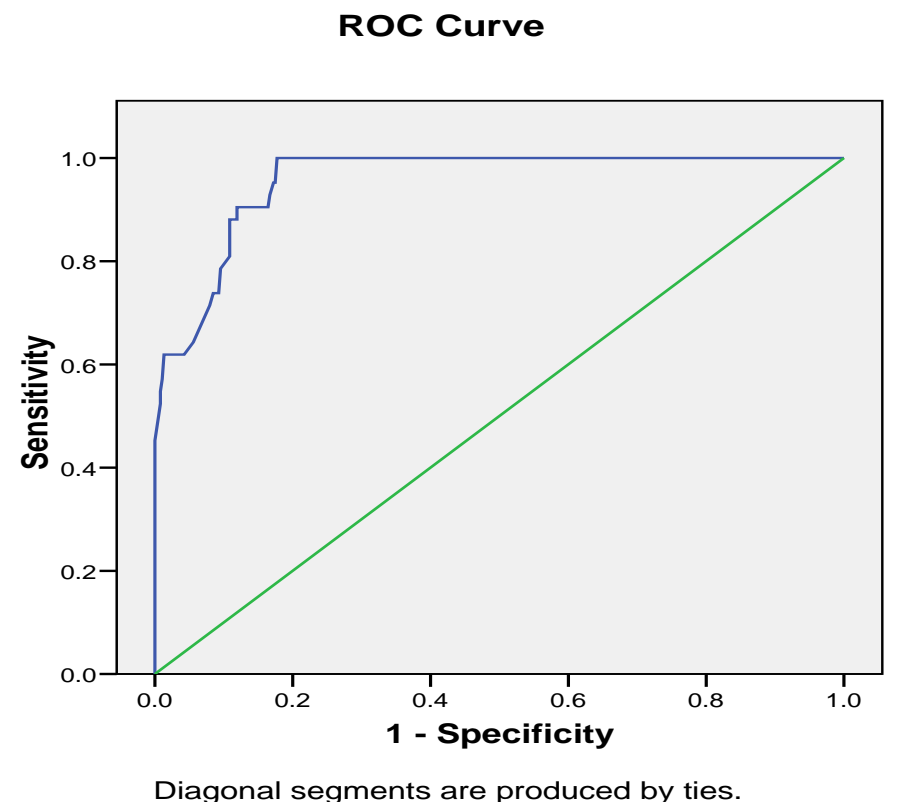

Figure (2): Receiver operator characteristics (ROC) curve was constructed for serum level of PI as predictor of development pre-eclampsia

Area under the curve was 0.968 [95\% CI (0.929 to 0.988), $\mathrm{p}<0.0001]$ (Table 8).

Table (8): Area under the ROC Curve for PI as Predictor of Pre-eclampsia

\begin{tabular}{|c|c|c|c|}
\hline & AUC & P(Area=0.5) & 95\% CI \\
\hline $\begin{array}{c}\text { PI as Predictor of Developing Pre- } \\
\text { eclampsia }\end{array}$ & 0.968 & $<0.0001$ HS & 0.929 to 0.988 \\
\hline
\end{tabular}

$\mathrm{AUC}=$ area under the curve, $\mathrm{HS}=$ highly significant, $95 \% \mathrm{CI}=95 \%$ Confidence Interval

The best cutoff point of PI as predictor of developing pre-eclampsia was $\geq$ 1.7 [sensitivity $100 \%$, specificity $84.33 \%$,
PPV42.1 \%, NPV 100\%, overall accuracy 95\%, LR+100, LR- 15.73] (Table 9).

Table (9): Diagnostic Accuracy of PI as Predictor of Pre-eclampsia

\begin{tabular}{|c|c|c|c|c|c|c|c|}
\hline & Sensitivity & specificity & PPV & NPV & $\begin{array}{c}\text { Overall } \\
\text { Accuracy }\end{array}$ & LR+ & LR- \\
\hline $\begin{array}{c}\text { PI as Predictor of } \\
\text { developing Pre- } \\
\text { eclampsia } \\
\geq 1.7\end{array}$ & $100 \%$ & $84.33 \%$ & $42.1 \%$ & $100 \%$ & $95 \%$ & 100 & 15.73 \\
\hline
\end{tabular}

PPV positive predictive value LR+ positive likelihood ratio

NPV negative predictive value LR- negative likelihood ratio

\section{DISCUSSION}

On follow up of the population of the study, 48 cases missed and 252 cases completed the study and 25 cases developed preeclampsia. Therefore, those previously recorded data were interpreted statistically as cases and remainder of 
subjects 227 women were considered normal.

In the present study, mean maternal age in pre-eclampsia cases was $23.25 \pm 4.13$ years, in comparison with normal which was $22.73 \pm 3.68$ years, but with no noted statistically significant differences between pre-eclampsia cases and normal as regard maternal age, furthermore there was no statistically significant difference between preeclamptic cases and normal as regard weight, height and body mass index. In agree with the findings of other studies such as (Hutchinson et al., 2010 and Roberts et al., 2017).

Our study demonstrated significant elevation in the mean concentration of sTNF- $\alpha$, at 11-13 weeks' gestation in patients subsequently developed preeclampsia than in cases that did not develop pre-eclampsia.

In accordance with our results, Moura et al. (2016) revealed significantly elevated TNF levels in first trimester maternal serum in early-PE, late-PE and $\mathrm{GH}$ groups in comparison to normotensive controls. However, TNF did not improve the detection rate of hypertensive disease achieved by maternal factors alone, and the addition of TNF to predictive models did not improve test performance for any pregnancy outcome. Increased levels of TNF- $\alpha$ have also been reported in the amniotic fluid of women in preterm labor, in comparison to women delivering at term.

TNF-R1 levels were found to rise with advancing gestation. In the second trimester, TNF-R1 levels were significantly higher in pregnancies complicated by PE and fetal growth restriction compared to pre-eclamptic pregnancies with normal birth weight. In addition, women with severe preeclampsia had the highest mean TNF-R1 levels throughout pregnancy, which were significantly higher than those of women with mild pre-eclampsia in the second and third trimesters, despite there being no significant difference in the first trimester. Overall, however, there were no differences in TNF-R1 levels among normotensive, hypertensive and preeclamptic women in any trimester (Schipper et al., 2010 and Moura et al., 2016).

In our study a correlation of TNF $-\alpha$ with personal and clinical parameters; out data analysis showed that there were no statistically significant correlations between serum TNF- $\alpha$ and other variables such as maternal age, BMI, weight or gestational age. While our data showed a significant positive correlation between serum TNF- $\alpha$ and each of systolic, diastolic and mean arterial blood pressure. On the other hand, there was highly statistically significant negative correlation between mean serum TNF- $\alpha$ and (Apgar score, GA at time of delivery). The performance of these tests was also compared using areas under receiver operator curves (AUC); ROC analysis which gave good discrimination and we found that the best cut off value of the serum TNF- $\alpha$ was $\geq 14 \mathrm{pg} / \mathrm{ml}$ and at this value we have Sensitivity $67.8 \%$; specificity 98\%; PPV 79.4\%; NPV 96.4\%.

In contrast to our study, Moura et al. (2016) stated that although the AUC for early-PE was slightly improved with TNF-R1 and with the combination of maternal factors and TNF-R1, these 
differences were not statistically significant.

Many limitations may affect this study; one of the limitations of their study was that it was not stratified on the basis of race. Another limitation is the small number of cases of early-onset preeclampsia. As regard pulsatility index (PI) statistically significant difference was observed between study groups, the mean pulsatility index (PI) of both uterine arteries was higher in pre-eclamptic cases than cases in normal group.

In addition, there were statistically significant positive correlations between mean PI and SBP, DBP, MBP. There were no statistically significant correlations between PI and other variables such as maternal age, BMI, weight or gestational age. On the other hand, there was highly statistically significant negative correlation between mean PI and score, GA at time of delivery.

ROC analysis was done, which gave good discrimination and we found that the best cutoff value of the mean uterine arteries was 1.7 and at this value we have $100 \%$ sensitivity, $84.33 \%$ specificity, 42.1\% PPV, $100 \%$ NPV. These findings were consistent to the findings of (Gomez et al., 2010 and Gujral and Nayar, 2016).

Gujral and Nayar (2016) found that outcome measures were PET with or without FGR and FGR without PET.

Martin et al. (2010) could obtain transabdominally satisfactory flow velocity waveforms from both uterine arteries in $96.1 \%$ of pregnant women who agreed to participate in the study and complete pregnancy outcomes were obtained. The essential findings were that the uterine artery mean PI $>$ the 95th centile had a sensitivity of $27.0 \%$ for PET (with or without FGR) and $11.7 \%$ for FGR, but the sensitivity was higher for these complications requiring delivery before 32 weeks (Martin et al., 2010 and Gujral and Nayar, 2016).

The findings of this study demonstrated the feasibility of assessing the uteroplacental circulation by transabdominal ultrasound at 11-14 weeks of gestation. Similarly, Gomez et al. (2010) conducted a prospective study on consecutive singleton pregnancies to establish reference values for 11-14 weeks UAD PI and to investigate the role of 11-14 weeks UAD PI in the prediction of hypertensive disorders and their associated complications. Using the 95th percentile in mean UAD PI as a cut-off, they identified $24 \%$ and $24.3 \%$ of the overall (term and preterm) preeclampsia and the "fetal growth restriction" cases, respectively. However, they defined fetal growth restriction as birth weight less than the 5th percentile for local references, in fact small for gestational age (SGA) including an unknown proportion of true FGR and constitutionally small, healthy infants.

A study was conducted to evaluate the predictive capacity of umbilical, cerebral and uterine artery Doppler in women admitted for pre-eclampsia (PE). They concluded that uterine artery Doppler was the best predictive parameter for perinatal outcome in pregnancies with PE and may be included as a primary surveillance test (Meler et al., 2010 and Parry et al., 2017).

This is concurrent with the results of our study as we concluded that uterine artery had a high sensitivity when it was 
measured as early as 11-14 weeks' gestation. Uterine artery PI can be used as a screening test to predict PE in early pregnancy before its development later to take precautions and to follow-up meticulously those women who have high uterine artery PI in early pregnancy.

Gomez et al. (2010) showed that the mean PI significantly decreased between 11 weeks and 34 weeks, then became stable until 41 weeks. Using the persistence of an abnormal mean PI in a sequential two-steps screening at 11-14 then 19-22 weeks, group with persistent abnormal mean PI from the first to the second trimester as the group with the greatest risk for adverse perinatal outcome defined as hypertension or FGR (Peixoto et al., 2016). Compared with pregnancies with a normal outcome, complicated pregnancies showed a higher mean PI in each of the two intervals studied. In addition, women in whom the uterine artery mean PI shifted from abnormal to normal between the two trimesters and women in whom the reverse shift occurred showed a similar intermediate risk (Peixoto et al., 2016).

Khaw et al. (2010) examined nulliparous women presenting consecutively with singleton pregnancies, similarly showed that11-14 weeks UAD PI increased in the group with preeclampsia and FGR and in the group with FGR but no pre-eclampsia, but not in the group with pre-eclampsia without FGR, confirming that elevated 11-14 weeks UAD PI correlated with complications related to uteroplacental insufficiency.

Inspite of the different methodology in the previous study, nevertheless it has postulated similar approach to support our study which is seeking for early predictive test for pre-eclampsia and we recommend further research to compare between PI and bilateral notching of uterine arteries in low risk pregnancies There was a strong agreement between Pulsatility index and diagnosis of preeclampsia and fetal growth restriction (Velauthar et al., 2014).

\section{CONCLUSION}

Preeclampsia accounts for $10 \%$ in our study. The combination of TNF- $\alpha$ and UA Doppler waveforms almost invariably predicts PET and other adverse pregnancy outcomes; therefore, when used together, biochemistry and ultrasound screening have the ability to improve the sensitivity of screening for PET. Early recognition of women of preeclampsia helps in identifying high risk women who may benefit from early prophylaxis and enhanced surveillance.

\section{REFERENCES}

1. Akbaş $M$, Şen $C$ and Calay $Z$ (2014): Correlation between First and Second Trimester Uterine Artery Doppler Velocimetry and Placental Bed Histopathology. International Scholarly Research Notices, 6:1-6.

2. Fisher SJ, McMaster $M$ and Roberts JM (2015): The placenta in normal pregnancy and preeclampsia. In: Chesley's hypertensive disorders in pregnancy. Pbl. Elsevier, Pp. 81112.

3. Gabal MS, Abousaif HA, Salah-eldin W and Abdelaziz AM (2017): Frequency of Hypertension Associated with Pregnancy among The Pregnant Women Attending Maternal and Child Care Centers in Belbeis. The Egyptian Journal of Community Medicine, 35:83-91.

4. Gomaa AA et al. (2019): Inhibition of adiposity and related metabolic disturbances by polyphenol-rich extract of Boswellia serrata gum through alteration of 
adipo/cytokine

profiles.

Inflammopharmacology. 27(3):549-559

5. Gomez O, Martinez JM and Figueras F. (2010): Uterine artery Doppler at 11-14 weeks of gestation to screen for hypertensive disorders and associated complications in an unselected population. Ultrasound in Obstetrics and Gynecology, 26:490-494.

6. Gujral K and Nayar S (2016): Prediction of Pre-eclampsia. Journal of Fetal Medicine, 3:55-61.

7. Hutchinson ES, Brownbill $P$ and Jones NW. (2010): Utero-placental haemodynamics in the pathogenesis of pre-eclampsia. Placenta, 30:634-641.

8. Khaw A, Kametas NA, Turan OM, Bamfo JE and Nicolaides KH. (2010): Maternal cardiac function and uterine artery Doppler at 11-14 weeks in the prediction of pre-eclampsia in nulliparous women. BJOG: An International Journal of Obstetrics \& Gynaecology, 115:369-376.

9. LaMarca B (2012): Endothelial dysfunction; an important mediator in the Pathophysiology of Hypertension during Preeclampsia. Minerva Ginecologica, 64:309-412.

10. Leal AM, Poon LCY, Frisova $V$ and Nicolaides H. (2010): First-trimester maternal serum tumor necrosis factor receptor-1 and pre-eclampsia. Ultrasound in Obstetrics and Gynecology, 33:135-141.

11. Martin AM, Bindra $R$, Curcio $P$, Cicero $S$ and Nicolaides KH. (2010): Screening for pre-eclampsia and fetal growth restriction by uterine artery Doppler at 11-14 weeks of gestation. Ultrasound in Obstetrics and Gynecology: The Official Journal of the International Society of Ultrasound in Obstetrics and Gynecology, 18:583-586.

12. Meler E, Figueras F and Mula R. (2010): Prognostic role of uterine artery Doppler in patients with preeclampsia. Fetal diagnosis and Therapy, 27:8-13.
13. Mesinas AAG and Marino ARF (2012): Ultrasonografia doppler de arterias uterinas entre las 11 a 14 semanas de edad gestacional, como predictor de preeclampsia. Horizonte Médico, 12:8-13.

14. Moura SBM, Park F and Murthi P (2016): TNF-R1 as a first trimester marker for prediction of pre-eclampsia. Journal of Maternal-Fetal and Neonatal Medicine, 29:897-903.

15. Parry S, Sciscione A and Haas DM. (2017): Role of early second-trimester uterine artery Doppler screening to predict small-forgestational-age babies in nulliparous women. American Journal of Obstetrics and Gynecology, 217:594-1.

16. Peixoto AB, Caldas TMR da $\mathrm{C}$ and Barros JJA. (2016): Reference ranges for the uterine arteries Doppler and cervical length measurement at 11-13 (+ 6) weeks of gestation in a Brazilian population. The Journal of Maternal-Fetal \& Neonatal Medicine, 29:2909-2914.

17. Roberts VHJ, Morgan TK and Bednarek P. (2017): Early first trimester uteroplacental flow and the progressive disintegration of spiral artery plugs: new insights from contrastenhanced ultrasound and tissue histopathology. Human Reproduction, 32:2382-2393.

18. Schipper EJ, Bolte AC, Schalkwijk CG, Van Geijn HP and Dekker GA. (2010): TNF-receptor levels in preeclampsia-results of a longitudinal study in high-risk women. The Journal of Maternal-Fetal \& Neonatal Medicine, 18:283-287.

19. Velauthar L, Plana MN, Kalidindi M, Zamora J, Thilaganathan B, Illanes SE, Khan KS, Aquilina $J$ and Thangaratinam S. (2014): First-trimester uterine artery Doppler and adverse pregnancy outcome: a meta-analysis involving 55974 women. Ultrasound in Obstetrics \& Gynecology, 43:500-507. 


\section{القيمة التنبؤية لمستوى معامل ذخر الورم ألثا باللدم ومؤشرات أشعة

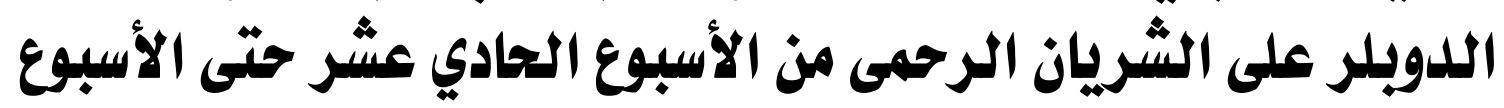

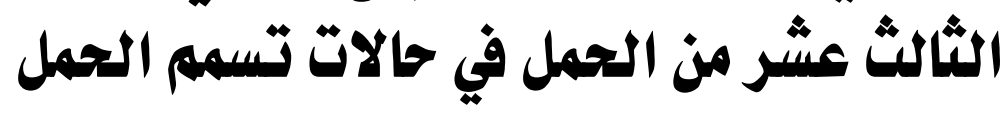

عبدالله عرفه طعيمى، إسماعيل محمد طلعت الجارحى، أسامه السعيد علي، نجاح محمد

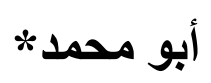

قسمي التوليد وأمراض النساء والباثولوجيا العامة*، كلية الطب، جامعة الأزهر

E-mail: $\underline{\text { abdallah_taemy9090@gmail.com }}$

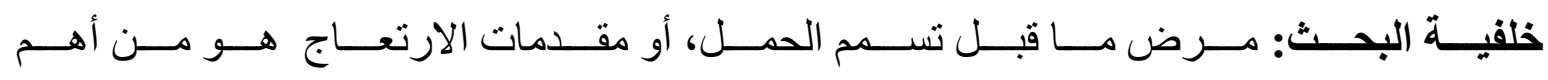

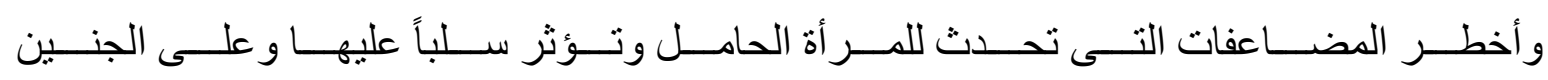

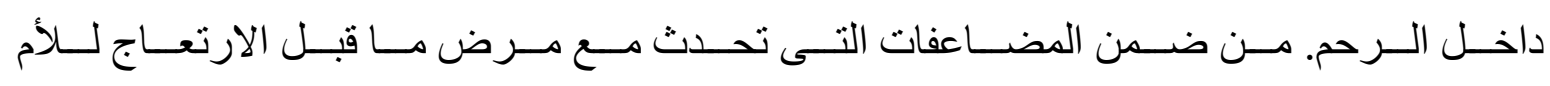

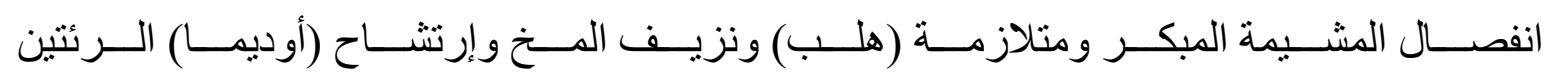

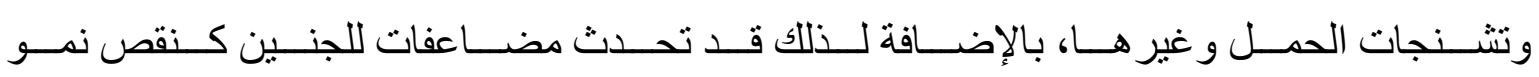

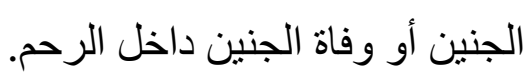

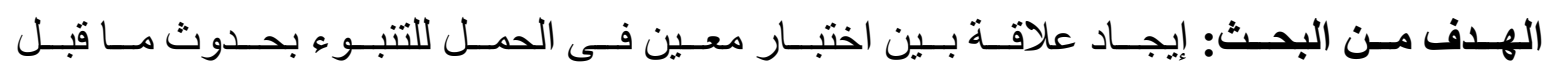

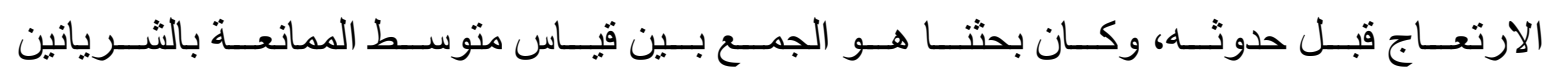

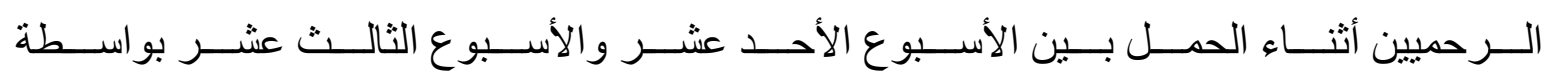

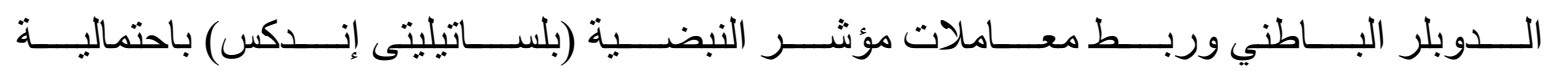
حدوث ما قبل الارتعاج وبين قياس نسبة عامل نخر الورم الفا.

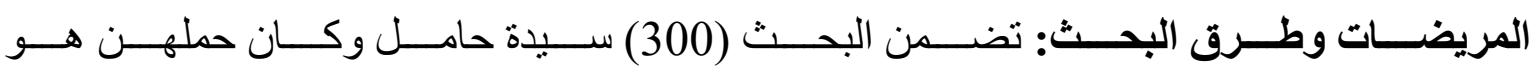

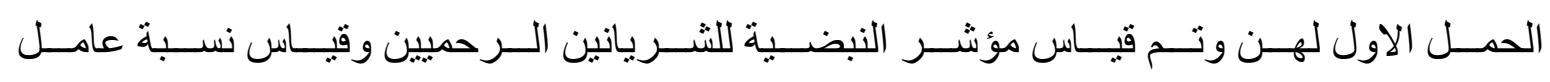

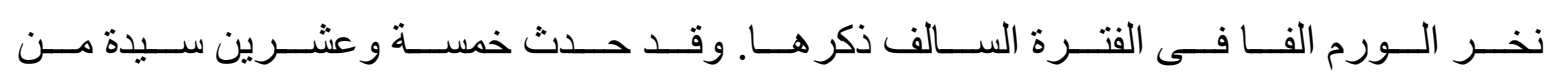

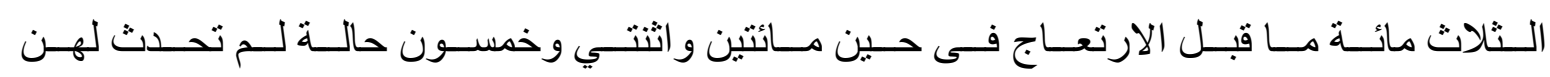

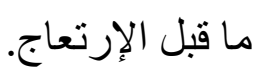

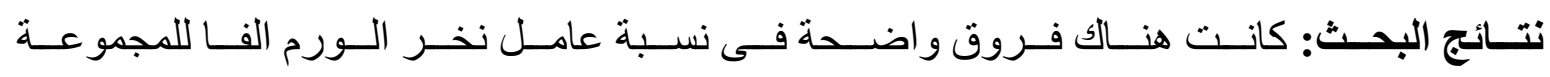

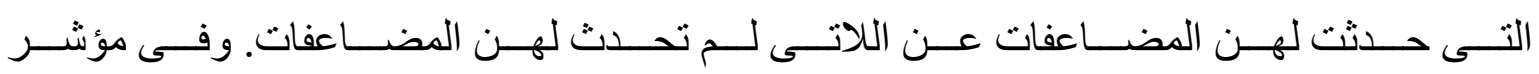




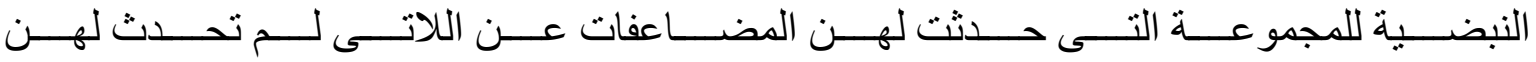

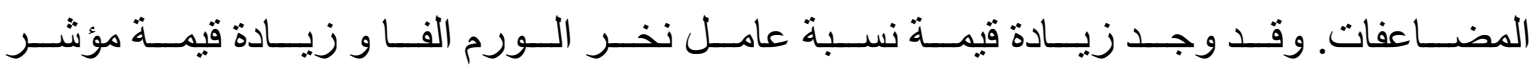

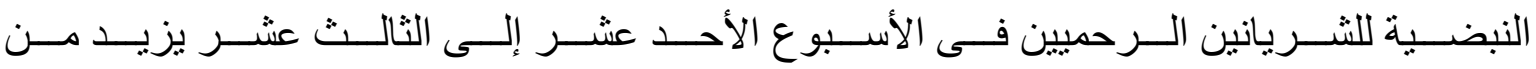

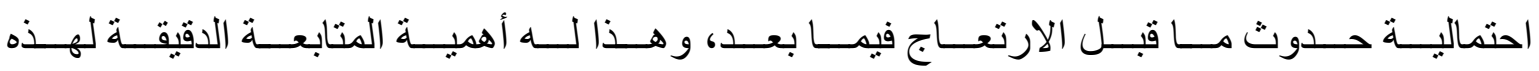

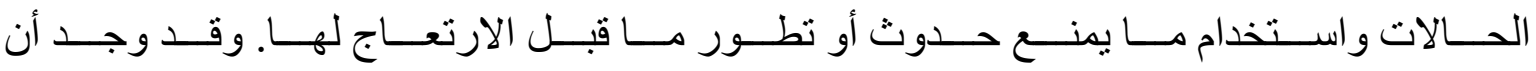

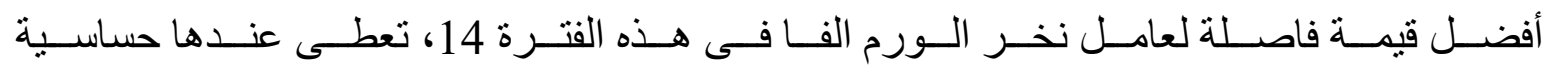

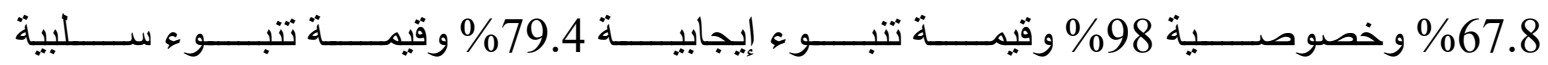

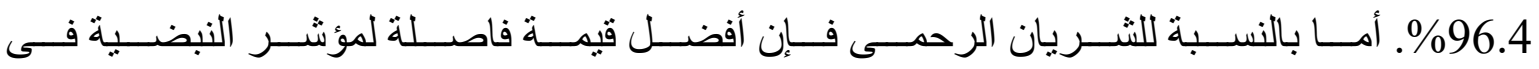

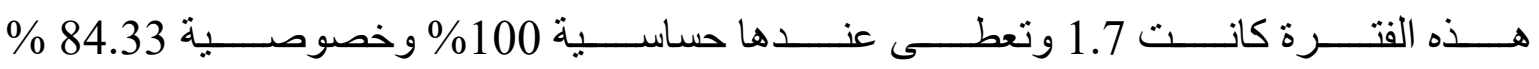
وقيمة تنبوء إيجابية 42.1\% وقيمة تتبوء سلبية 100\%.

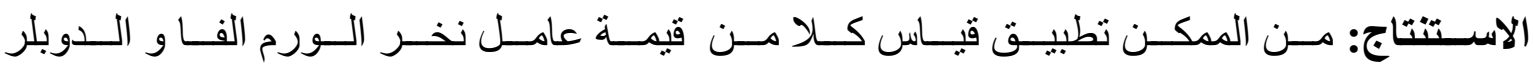

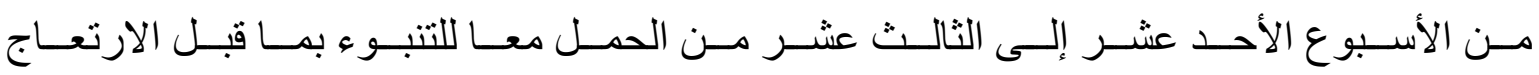
وذللك لاتخاذ الاحتياطات الو اجبة لتنافى الكثير من المضاعفات للأم و الجنين.

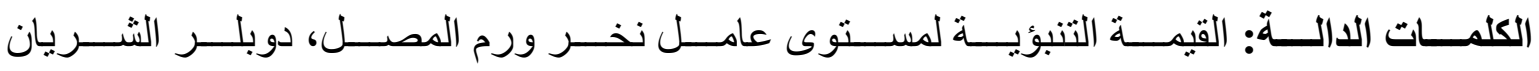

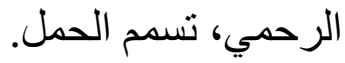

